\title{
Association of simple renal cysts and chronic kidney disease with large abdominal aortic aneurysm
}

\author{
Milena Miszczuk ${ }^{1 \dagger}$, Verena Müller ${ }^{2 \dagger}$, Christian E. Althoff ${ }^{3}$, Andrea Stroux $^{4,5}$, Daniela Widhalm ${ }^{1}$, Andy Dobberstein ${ }^{1}$,
} Andreas Greiner ${ }^{1}$, Helena Kuivaniemi ${ }^{5}$ and Irene Hinterseher ${ }^{1 *}$ (i)

\begin{abstract}
Background: Abdominal aortic aneurysms (AAA) primarily affect men over 65 years old who often have many other diseases, with similar risk factors and pathobiological mechanisms to AAA. The aim of this study was to assess the prevalence of simple renal cysts (SRC), chronic kidney disease (CKD), and other kidney diseases (e.g. nephrolithiasis) among patients presenting with AAA.

Methods: Two groups of patients (97 AAA and 100 controls), with and without AAA, from the Surgical Clinic Charite, Berlin, Germany, were selected for the study. The control group consisted of patients who were evaluated for a kidney donation $(n=14)$ and patients who were evaluated for an early detection of a melanoma recurrence $(n=86)$. The AAA and control groups were matched for age and sex. Medical records were analyzed and computed tomography scans were reviewed for the presence of SRC and nephrolithiasis.

Results: SRC (74\% vs. 57\%; $\mathrm{p}<0.016)$ and CKD $(30 \%$ vs. $8 \%$; $\mathrm{p}<0.001)$ were both more common among AAA than control group patients. On multivariate analysis, CKD, but not SRC, showed a strong association with AAA.

Conclusions: Knowledge about pathobiological mechanisms and association between CKD and AAA could provide better diagnostic and therapeutic approaches for these patients.
\end{abstract}

Keywords: Abdominal aortic aneurysm, renal cyst, chronic kidney disease

\section{Background}

Abdominal aortic aneurysm (AAA) is the most common type of aneurysm, and is defined as an abdominal aortic diameter $>3 \mathrm{~cm}[1]$. According to recent literature, the prevalence of AAA has decreased in the last decades and is $1-2 \%$ [2]. This change can be primarily attributed to a decreased prevalence of smoking [2,3]. The prevalence of AAA, however, increases with age and is $4.1 \%-14.2 \%$ in men and $0.35-6.2 \%$ in women $>65$ years $[4,5]$.

\footnotetext{
* Correspondence: irene.hinterseher@charite.de

${ }^{\dagger}$ Milena Miszczuk and Verena Müller contributed equally to this work. ${ }^{1}$ Vascular Surgery Clinic, Klinik für Gefäßchirurgie, Campus Charité Benjamin Franklin, Hindenburgdamm 30, 12200 Berlin, Germany

Full list of author information is available at the end of the article
}

As AAA is asymptomatic in the majority of cases [6], it is often initially detected as an incidental finding during ultrasound or computed tomography $(\mathrm{CT})$ examinations. Unfortunately, many AAA cases remain undetected until rupture. The mortality rate of a ruptured AAA is estimated to be $74-90 \%[7,8]$, with a $32-$ $83 \%$ pre-hospital mortality rate $[7,9]$. One way to reduce this trend, is to implement a national AAA screening program to detect AAA before rupture [10]. Such a program was launched successfully in the USA in 2007 [11] and in the Great Britain in 2009 [12].

A number of risk factors for AAA have been identified. The four primary risk factors are male sex, age $>65$ years, smoking and a positive family history [13-18].

(c) The Author(s). 2020 Open Access This article is licensed under a Creative Commons Attribution 4.0 International License, which permits use, sharing, adaptation, distribution and reproduction in any medium or format, as long as you give appropriate credit to the original author(s) and the source, provide a link to the Creative Commons licence, and indicate if changes were made. The images or other third party material in this article are included in the article's Creative Commons licence, unless indicated otherwise in a credit line to the material. If material is not included in the article's Creative Commons licence and your intended use is not permitted by statutory regulation or exceeds the permitted use, you will need to obtain permission directly from the copyright holder. To view a copy of this licence, visit http://creativecommons.org/licenses/by/4.0/ The Creative Commons Public Domain Dedication waiver (http://creativecommons.org/publicdomain/zero/1.0/) applies to the data made available in this article, unless otherwise stated in a credit line to the data. 
Several diseases appear to often co-exist with AAA, including chronic obstructive pulmonary disease (COPD) $[13,19,20]$, different types of hernia [20], gallstones [21], and simple renal cysts (SRC) [22]. SRC is a common disease, with increased prevalence in older patients, affecting $24-27 \%$ of those $>50$ years of age [23, 24]. In older individuals, SCRs are even more common; Carrim et al. found an overall prevalence of $41 \%$ [25], while Chang et al. reported a prevalence of $35 \%$ in $>60$-year olds [26].

The co-occurrence of AAA and SRC [22, 27] can be explained by shared risk factors, e.g. older age $[26,28$, 29], male sex [25, 30], hypertension [31] and smoking [26]. Ito et al. [22] stated "the presence of renal cysts shows the strongest independent association with $A A A$ among patients belonging to the 65 to 74 years old group and over 75 years old group". The exact pathogenesis of SRC remains unclear, but it is intriguing that both diseases demonstrate increased matrix metalloproteinase (MMP) levels, in the aortic wall in AAA patients [32] and in the cystic fluid in patients with SRCs [33].

Given the potentially shared pathophysiology between SRC and AAA, the primary aim of this study was to assess the prevalence of SRC and other kidney diseases among AAA patients, and compare the results to a group of age- and sex-matched non-AAA patients from the same hospital.

\section{Methods}

The study was approved by the Charité Ethics Committee (approval number: EA1/309/16). Since the study was a retrospective review of medical and imaging records, no informed consent from the patients was required according to the study approval.

\section{Study groups}

This study was a retrospective review of patients' medical records including radiology records. Two groups of patients were compared in the study. All 197 patients had undergone a computed tomography-angiography (CTA) scan. The first group $(\mathrm{n}=97)$ included patients, who underwent AAA surgery in 2004- 2012 at Charité Clinic Campus Mitte in Berlin, Germany. Surgeries were performed either as elective (unruptured AAA; $n=92$ ) or as emergency (ruptured AAA; $n=5$ ) operations. The exclusion criteria were an abdominal aortic diameter $<3$ $\mathrm{cm}$, AAA operation before 2004, diagnosis of rare genetic disorder such as Marfan syndrome or Ehlers-Danlos syndrome, and the presence of any other arterial aneurysm. Further exclusion criterion was the presence of genetic kidney diseases, such as autosomal dominant polycystic kidney disease (ADPKD). For the AAA patients, the pre-operative scans were used.
The control group $(n=100)$ included patients without AAA investigated at the Institute of Radiology of Charite Clinic, Berlin, Germany, and consisted of patients who were evaluated for a kidney donation in 2005 - 2014 (n $=14$ ) and patients who were evaluated for an early detection of a melanoma recurrence $(\mathrm{n}=86)$. We chose this group of patients as a control group for the following reasons: 1 ) they were also examined by abdominal CTA; 2) melanoma is an age-related disease and a disease of a different organ, not the aorta; and 3) they were from the same hospital system. Also, there were no differences in the mean height, weight, or BMI between the AAA and control groups [34].

AAA patients and controls were matched on sex and age ( \pm 2 years). For the AAA patients, age at the time of the first AAA diagnosis was used for this analysis. If this information was missing, age at the time of AAA surgery was taken. For the control group, age during the CTA scan was used for the analysis.

\section{Clinical data}

For the analysis of the CTA scans, Centricity eRadCockpit Software (GE Healthcare, Chalfont St Giles, Great Britain) was used. First, written reports from boardcertified radiologists were reviewed by one of the authors (M.M.). As SRCs are common, sometimes they were not described as a diagnosis in the report. For that reason, the CTA scans were assessed again for the presence of SRC (Fig 1) and kidney stones. Results were discussed with a board-certified radiologist (C.E.A.).

Individual data on all study patients for all variables used in the study are available in the Additional file 1 .

SRC (ICD-10: N28.1) were divided into subgroups according to their size: Group 1: $\leq 1 \mathrm{~cm}$; Group 2: $1.01-$ $3.0 \mathrm{~cm}$; Group 3: $3.1-5.0 \mathrm{~cm}$; and Group 4: $>5 \mathrm{~cm}$. SRCs were also classified using Bosniak Classification System: I: simple, benign cysts; II: minimally complicated benign cystic lesions; III: more complicated cystic lesions; and IV: cystic carcinoma [35].

Nephrolithiasis (ICD-10: N20.0) was defined as a presence of kidney stones on the CTA scans.

Additional patient data [34] were collected from the medical records using the patient data management program SAP (SAP SE, Walldorf, Germany). Information about the presence of chronic kidney disease (CKD) was collected. CKD was defined as a presence of the following ICD-10 diagnostic codes in the medical records: N18.1 for CKD stage 1, N18.2 for CKD stage 2, N18.3 for CKD stage 3, N18.4 for CKD stage 4, N18.5 for CKD stage 5, and Z94.0 for renal transplantation (Additional file 2). Additional diseases in the same study groups are described in another study [34]. 


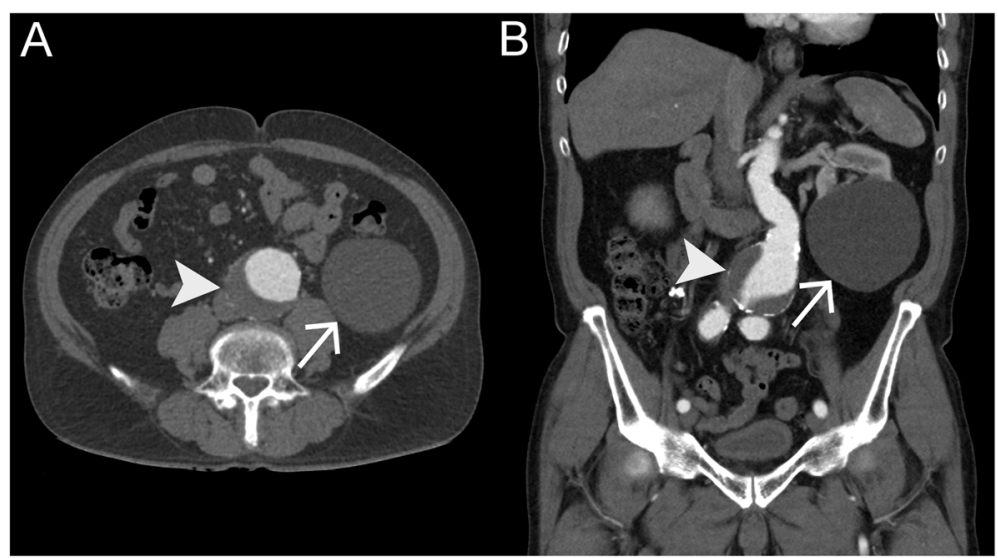

Fig. 1 Simple renal cyst detected in a CT scan. Contrast-enhanced CT scan of the abdomen in axial (a) and coronal (b) plane, arterial phase, demonstrates an AAA (arrowhead) with mural thrombus and patent lumen and a large hypodense mass on the lower left renal pole, representing a simple renal cyst (arrow)

\section{Statistical analysis}

For statistical analyses SPSS Statistics Version 22 for Windows (IBM, Armonk, New York, USA) was used. First, a univariable analysis was carried out. For quantitative variables, the mean, median, standard deviation, minimal and maximal values were determined. The categorical variables were analyzed using cross-tabulation. The differences between the two groups were determined using Mann-Whitney $U$ test or chi-squared test (Fisher's exact test) where appropriate. A difference was defined significant, if $p \leq 0.05$.

The univariable analysis was followed by a multivariable analysis to identify independent risk factors. Significant values from the univariable analysis were included in a multiple logistic regression model. This included the following parameters: ever smoker, peripheral artery disease (PAD), pack years of smoking, incisional hernia, any hernia, congestive heart failure, American Society of Anesthesiologists (ASA) score, diabetes mellitus, coronary bypass, creatinine, COPD, current smoker, coronary artery disease, diverticulosis, platelet count [34] and SRC. Parameters with $>50 \%$ of the values missing were excluded from the analysis. A forward and backward analysis was performed. Odds ratios (OR) and a 95\% confidence intervals (CI) were calculated. The analysis was carried out on the entire study group as well as stratified by age ( $<65$ and $\geq 65$ years).

\section{Results}

Our study included 97 (76 male and 21 female) AAA patients and 100 (79 male and 21 female) age- and sexmatched controls. Altogether, 29.9\% AAA and 8\% control patients had CKD diagnosis in their medical records $(p<0.001$; Table 1$)$. The distribution of CKD stages was also statistically significantly different between the study groups ( $p=0.002$; Table 1$)$. One AAA patient received a renal transplantation due to the CKD. Nephrolithiasis was found in $2.1 \%$ of the AAA and $7.1 \%$ of the control patients $(p=0.170)$. SRCs were found amongst $74.2 \%$ AAA patients and $57 \%$ controls, resulting in a statistically significant difference (Table $1 ; p=0.016$ ).

In the right kidney, SRCs were found in $59.8 \%$ of AAA patients and in $46 \%$ of controls $(p=0.064)$. In the AAA group, $47.4 \%$ of patients had $1-4$ SRCs, and $12.4 \%$ of patients had $\geq 5$ SRCs. In the control group, these numbers were $41 \%$ and $5 \%$, respectively ( $p=0.05$, for both comparisons; Table 1). In the right kidney, SRCs $\leq 1 \mathrm{~cm}$ were significantly more common among AAA than control patients $(p<0.001$; Table 2$)$.

In the left kidney, SRCs were found in $62.5 \%$ of AAA and $33 \%$ of control patients $(p<0.001$; Table 1$)$. In the AAA group, $50 \%$ of patients had 1-4 SRCs, and $12.5 \%$ of patients had $\geq 5$ SRCs. In the control group, these numbers were $29 \%$ and $4 \%$, respectively $(p<0.001$, for both variables; Table 1). In the left kidney, both small $(\leq 1 \mathrm{~cm} ; p<0.001)$ and medium size $(1-3 \mathrm{~cm} ; \mathrm{p}=0.020)$ SRCs were significantly more common among AAA than control patients (Table 3). In the AAA group, we also found two patients with SRCs classified as Bosniak II and two patients with SCRs classified as Bosniak III. In the control group, one patient each with Bosniak II and Bosniak III were found. There were 46 (47.4\%) AAA and $22(22 \%)$ control group patients who had bilateral SRC disease, whereas 25 (25.8\%) AAA and 34 (34\%) control patients had SRCs in only the left or right kidney $(p=0.001)$.

In multivariable analyses we found a strong independent association between $\mathrm{AAA}$ and $\mathrm{CKD}(\mathrm{OR}=5.528$; 95\% $\mathrm{CI}=$ 1.732-17.647; $\mathrm{p}=0.004)$. We found no direct association between SRC and AAA (OR = 1.693; 95\%CI = 0.615-4.658; $p=0.308$ ), when adjusting for other variables.

We also carried out the analyses separately for those patients $<$ and $\geq 65$ years. In patients $<65$ 
Table 1 Comparison of simple renal cysts and chronic kidney disease between study groups

\begin{tabular}{|c|c|c|c|c|c|}
\hline \multirow[t]{2}{*}{ Variable } & \multicolumn{2}{|l|}{ AAA group } & \multicolumn{2}{|l|}{ Control group } & \multirow[t]{2}{*}{$p^{a}$} \\
\hline & $\begin{array}{l}\text { With variable } \\
n\end{array}$ & $\begin{array}{l}\text { Data available } \\
n\end{array}$ & $\begin{array}{l}\text { With variable } \\
n\end{array}$ & $\begin{array}{l}\text { Data available } \\
n\end{array}$ & \\
\hline CKD, all stages ${ }^{b}$ & 29 & 97 & 8 & 100 & $<0.001$ \\
\hline CKD stage 1/2/3/4/5/RTX ${ }^{C}$ & $5 / 9 / 11 / 1 / 2 / 1$ & 97 & $1 / 4 / 3 / 0 / 0 / 0$ & 100 & 0.002 \\
\hline Nephrolithiasis & 2 & 97 & 7 & 98 & 0.170 \\
\hline SRC (both right and left kidney) & 72 & 97 & 57 & 100 & 0.016 \\
\hline SRC, right kidney only & 58 & 97 & 46 & 100 & 0.064 \\
\hline $1-4$ SRC in right kidney ${ }^{d}$ & 46 & 97 & 41 & 100 & 0.05 \\
\hline$>5$ SRC in right kidney ${ }^{d}$ & 12 & 97 & 5 & 100 & 0.05 \\
\hline SRC, left kidney only ${ }^{d}$ & 60 & 97 & 33 & 100 & $<0.001$ \\
\hline $1-4$ SRC in left kidney ${ }^{d}$ & 48 & 97 & 29 & 100 & $<0.001$ \\
\hline$>5$ SRC in left kidney ${ }^{d}$ & 12 & 97 & 4 & 100 & $<0.001$ \\
\hline
\end{tabular}

\section{${ }^{\mathrm{a} C h i}$-square test}

${ }^{b}$ Defined as presence of ICD-10 code in medical records: N18.1 for CKD stage 1, N18.2 for CKD stage 2, N18.3 for CKD stage 3, N18.4 for CKD stage 4, N18.5 for CKD stage 5 or Z94.0 for renal transplantation.

'Defined as presence of kidney stones (ICD-10: N20.0) on the CTA scans.

${ }^{\mathrm{d}}$ Defined as presence of simple renal cysts (ICD-10: Q61.9) on the CTA scans.

CKD Chronic kidney disease; SRC Simple renal cyst; $R T X$ Renal transplantation.

years (29 AAA and 21 control patients), CKD was the only parameter with a statistically higher prevalence in the AAA group $(p=0.001$; Table 4$)$. In patients $\geq$ 65 years (68 AAA and 79 control patients), AAA patients suffered significantly more often from CKD $(p$ $=0.002)$, SRC $(p=0.018)$ and SRC on left kidney only $(p=<0.001$; Table 5$)$. Further, CKD showed an independent association with AAA in multivariate analysis in this older age group $(\mathrm{OR}=6.503 ; 95 \% \mathrm{CI}$ $=2.088-20.255 ; p=0.001)$.

\section{Discussion}

The main findings of our study were that CKD was more frequent in AAA than age- and sex-matched control patients and showed a strong association with AAA in multivariable analysis, which included ever smoker, PAD, pack years, incisional hernia, any hernia, congestive heart failure, ASA score, diabetes mellitus, coronary bypass, creatinine, COPD, current smoker, coronary artery disease, diverticulosis, platelet count and SRC. AAA patients also had a higher rate of SRC, but SRCs were not independently associated with AAA.

Our study demonstrated a strong association between AAA and CKD with $29.9 \%$ of the AAA and only $8 \%$ of the age- and sex-matched control patients diagnosed with CKD. The AAA patients also exhibited a more advanced CKD stage. Previously published studies reported a wide range of CKD prevalence (3-65\%) among AAA patients [20, 36-39]. Alnassar et al. [36] and Pitoulias et al. [20] found no significant difference in the prevalence of CKD between AAA and PAD patients [20,36]. However, patients with a large AAA $(>5.5 \mathrm{~cm})$ had a significantly higher rate of CKD than patients with a small AAA (13\% vs. $2 \%$ ) [20]. Approximately half (52.6\%) of the AAA patients in our study had a large AAA $(>5.5$ $\mathrm{cm}$ ) and all were operated on for AAA, and the rate of CKD was over four times as high as the rate in the study of Pitoulias et al [20]. Furthermore, similar to the

Table 2 Simple renal cysts in the right kidney classified according to their size

\begin{tabular}{|c|c|c|c|c|c|c|c|}
\hline \multirow{2}{*}{$\begin{array}{l}\text { SRC } \\
\text { classification } \\
\text { based on size }\end{array}$} & \multicolumn{3}{|l|}{ AAA group } & \multicolumn{3}{|l|}{ Control group } & \multirow[t]{2}{*}{$p^{a}$} \\
\hline & $\begin{array}{l}\text { Number of SRC per } \\
\text { patient } \\
\text { Mean+/-SD }\end{array}$ & $\begin{array}{l}\text { Median number of SRC per } \\
\text { patient }\end{array}$ & $\begin{array}{l}\text { Data } \\
\text { available } \\
n\end{array}$ & $\begin{array}{l}\text { Number of SRC per } \\
\text { patient } \\
\text { Mean+/-SD }\end{array}$ & $\begin{array}{l}\text { Median number of SRC per } \\
\text { patient }\end{array}$ & $\begin{array}{l}\text { Data } \\
\text { available } \\
n\end{array}$ & \\
\hline$\leq 1 \mathrm{~cm}$ & $1.15 \pm 1.86$ & 0 & 97 & $0.50 \pm 1.45$ & 0 & 100 & $<0.001$ \\
\hline $\begin{array}{l}1.1 \mathrm{~cm}-3.0 \\
\mathrm{~cm}\end{array}$ & $0.43 \pm 0.95$ & 0 & 97 & $0.41 \pm 0.79$ & 0 & 100 & 0.99 \\
\hline $\begin{array}{l}3.1 \mathrm{~cm}-5.0 \\
\mathrm{~cm}\end{array}$ & $0.10 \pm 0.34$ & 0 & 97 & $0.05 \pm 0.26$ & 0 & 100 & 0.15 \\
\hline$>5 \mathrm{~cm}$ & $0.02 \pm 0.14$ & 0 & 97 & $0.04 \pm 0.20$ & 0 & 100 & 0.68 \\
\hline
\end{tabular}

${ }^{\mathrm{a}}$ Mann-Whitney U test

SRC Simple renal cyst 
Table 3 Simple renal cysts in the left kidney classified according to their size

\begin{tabular}{|c|c|c|c|c|c|c|c|}
\hline \multirow{2}{*}{$\begin{array}{l}\text { SRC } \\
\text { classification } \\
\text { based on size }\end{array}$} & \multicolumn{3}{|l|}{ AAA } & \multicolumn{3}{|l|}{ Controls } & \multirow[t]{2}{*}{$p^{a}$} \\
\hline & $\begin{array}{l}\text { Number of SRC per } \\
\text { patient } \\
\text { Mean+/-SD }\end{array}$ & $\begin{array}{l}\text { Median number of SRC per } \\
\text { patient }\end{array}$ & $\begin{array}{l}\text { Data } \\
\text { available, } \\
n\end{array}$ & $\begin{array}{l}\text { Number of SRC per } \\
\text { patient } \\
\text { Mean+/-SD }\end{array}$ & $\begin{array}{l}\text { Median number of SRC per } \\
\text { patient }\end{array}$ & $\begin{array}{l}\text { Data } \\
\text { available, } \\
n\end{array}$ & \\
\hline$\leq 1 \mathrm{~cm}$ & $1.28 \pm 2.08$ & 1 & 96 & $0.37 \pm 1.17$ & 0 & 100 & $<0.001$ \\
\hline $\begin{array}{l}1.1 \mathrm{~cm}-3.0 \\
\mathrm{~cm}\end{array}$ & $0.56 \pm 0.95$ & 0 & 96 & $0.30 \pm 0.73$ & 0 & 100 & 0.02 \\
\hline $\begin{array}{l}3.1 \mathrm{~cm}-5.0 \\
\mathrm{~cm}\end{array}$ & $0.10 \pm 0.31$ & 0 & 96 & $0.04 \pm 0.20$ & 0 & 100 & 0.10 \\
\hline$>5 \mathrm{~cm}$ & $0.01 \pm 0.10$ & 0 & 96 & $0.00 \pm 0.00$ & 0 & 100 & 0.49 \\
\hline
\end{tabular}

${ }^{\mathrm{a}}$ Mann-Whitney $\mathrm{U}$ test

SRC Simple renal cyst

findings by Chun et al. [38] and Takeuchi et al. [39], our study demonstrated an independent association of AAA and CKD in multivariable analysis, not seen in the study by Pitoulias et al. [20].

We estimated the prevalence of SRC to be $74.2 \%$ in the AAA and $57 \%$ in the control group. Based on previous literature, the SRC prevalence in general population varies $4.2-41 \%[25,28]$, which is lower than in the current study (Table 6). Similarly, the SRC prevalence among AAA patients in the current study was higher than in most of the previous studies, which reported a prevalence of $38-69 \%$ among AAA patients and 19-45\% for controls [20, 22, 27, 40-42]. A recent study by Brownstein et al. [42] analyzed a total of 35,498 patients who underwent both chest and abdominal CT imaging during a 4-year period. Altogether $18 \%$ of these patients had SRC and $2.6 \%$ had AAA. Compared with the matched population without SRC, patients with SRC demonstrated an increased prevalence of AAA ( $8 \%$ vs. 3\%). They were also more likely to have thoracic, ascending and descending aortic aneurysms or dissections [42]. Five previous studies found an independent association between AAA and SRC in a multivariable analysis [20, $22,27,40,42]$, but we could not confirm this in our study. However, three of those studies [22, 40, 42] examined a significantly larger patient group.
Ito et al. [22] found an association between AAA and SRC in their multivariable analysis, but only in patients $>65$ years. Because of low patient numbers, we were not able to analyze the patients $<65$ years separately. Our analyses with the older patients ( $\geq 65$ years) showed a significantly higher prevalence of CKD in the AAA group ( $31 \%$ vs. $10 \%)$ with an independent association in the multivariate analysis $(\mathrm{OR}=6.5, p=0.001)$. Also, SRC were significantly more frequent in the AAA group ( $81 \%$ vs. $62 \%, p=0.018$ ), however, we were not able to confirm an independent association in the multivariate analysis. Therefore, our analysis partially confirm the results previously published by Ito et al. [22]. Age is also an important risk factor for SRC. Prior studies have confirmed that SRC develops mostly at older age $[24,25,28$, 29, 40, 41], and Ito et al. [22] and Yaghoubian et al. [27] found a significant difference in the age of patients with and without SRC in the general population.

SRC and AAA share some common risk factors, e.g. older age, male sex and hypertension [25, 26, $28-31]$, and some studies also mention smoking as a possible risk factor for SRC [26]. Molecular studies suggest that MMPs play a role in the pathophysiology of SRC and AAA [33]. Furthermore, one study on 108 autopsies showed a correlation between the diameter of the abdominal aorta and the number of SRC [43].

Table 4 Univariate analysis of AAA in patients $<65$ years old

\begin{tabular}{llll}
\hline Variable & AAA $(n=29)$ & Controls $(n=21)$ & $\mathrm{p}$ \\
\hline Age (mean \pm SD), years & $58.7 \pm 5.7$ & $59.0 \pm 4.8$ & - \\
AAA diameter at first diagnosis (mean \pm SD), mm & $54.3 \pm 19.1$ & - & - \\
AAA diameter at surgery (mean \pm SD), mm & $62.1 \pm 16.3$ & $85.7 \%$ & 0.00 \\
Male & $93.1 \%$ & $38.1 \%$ & 0.638 \\
Chronic kidney disease & $27.6 \%$ & $28.6 \%$ & 0.001 \\
Simple renal cysts & $58.6 \%$ & $23.8 \%$ & 0.252 \\
Simple renal cysts right kidney & $51.7 \%$ & 0.148 \\
Simple renal cysts left kidney & $39.3 \%$ & 0.359 \\
\hline
\end{tabular}

Group size not large enough to perform a multivariate analysis. 
Table 5 Univariate and multivariate analysis of AAA in patients $>65$ years old

\begin{tabular}{|c|c|c|c|c|c|c|}
\hline \multirow[t]{2}{*}{ Variable } & \multicolumn{3}{|c|}{ Univariate analysis } & \multicolumn{3}{|c|}{ Multivariate analysis } \\
\hline & $\mathrm{AAA}(n=68)$ & Controls $(n=79)$ & $\mathrm{p}$ & $\mathrm{OR}$ & $95 \% \mathrm{Cl}$ & $\mathrm{p}$ \\
\hline Age (mean $\pm S D)$, years & $73.3 \pm 5.8$ & $74.5 \pm 6.1$ & 0.169 & - & - & - \\
\hline AAA diameter at first diagnosis (mean $\pm \mathrm{SD}$ ), $\mathrm{mm}$ & $50.9 \pm 13.0$ & - & - & - & - & - \\
\hline AAA diameter at surgery (mean \pm SD), $\mathrm{mm}$ & $57.6 \pm 10.1$ & - & - & - & - & - \\
\hline Male & $72.1 \%$ & $77.2 \%$ & 0.568 & - & - & - \\
\hline CKD & $30.9 \%$ & $10.1 \%$ & 0.002 & 6.503 & $2.088-20.255$ & 0.001 \\
\hline SRC & $80.9 \%$ & $62.0 \%$ & 0.018 & 2.5 & $0.736-8.497$ & 0.142 \\
\hline SRC right kidney & $63.2 \%$ & $50.6 \%$ & 0.136 & - & - & - \\
\hline SRC left kidney & $72.1 \%$ & $35.4 \%$ & $<0.001$ & - & - & - \\
\hline
\end{tabular}

Further research on kidney diseases and AAA is not only of academic, but also of clinical interest. Nowadays, the majority of AAA are repaired using endovascular aneurysm repair (EVAR), which requires a contrast agent administration, known to be nephrotoxic. Only one study has investigated the kidney function in patients with SRC after EVAR [41], and found that patients with SRC had slightly higher creatinine levels, both before and after surgery, but the difference was not statistically significant [41]. There was no significant difference in the creatinine levels after EVAR [41], leading to the conclusion that kidney function is not affected by the presence of SRC. As we have reported previously, in the current study population, the AAA group patients had significantly higher creatinine levels than the control group patients [34].

Nephrolithiasis is a common problem in the elderly population. A higher prevalence of nephrolithiasis has been reported in patients with SRC [26] and ADPKD [44]. The relationship between renal stones and AAA has not been investigated previously. As SRC appear frequently in AAA patients [22, 27, 45], one might expect that nephrolithiasis affects AAA patients as well. In our study population, we found no association between AAA and nephrolithiasis. Nonetheless, when examining a patient with a renal colic, one should consider a symptomatic or ruptured AAA as a potential differential diagnosis.

The association between AAA and CKD also requires further research by examining the role CKD plays on the development and progression of AAA. It has been reported that blood vessel walls in patients with CKD are thinner, which can increase the risk for rupture [46]. The co-occurrence of AAA and CKD also has several clinical implications, since CKD increases the rate of complications after surgery [47]. The clot inside the aneurysm sac can also impair the blood perfusion of renal arteries (e.g. by embolization).

Further, CKD patients are known to suffer from vitamin D deficiency [48]. Wong et al. [49] reported that vitamin $\mathrm{D}$ deficiency may be a potential risk factor for AAA, but the association was weak with $\mathrm{OR}=1.23$ $(95 \% \mathrm{CI}=0.87-1.73)$. Thus, the literature on the association between AAA and vitamin D levels is still sparse and additional studies are required.

The main limitation of our study is the fact that this was a retrospective single-center study with a small number of patients and controls. Another possible limitation is the fact that the control group consisted of patients with melanoma and those evaluated for kidney donation and their comorbidity profile might not be representative of the general population. Especially patients with melanoma may have had a stronger sun exposure and therefore could have higher vitamin D levels which are potentially associated with AAA and CKD. However, a comparison of our two control groups (kidney donation vs. melanoma) showed no difference in the prevalence of CKD or SRC between these two groups (both $p$ $>0.05$, not shown). Therefore, we assume that the potential bias caused by the vitamin $\mathrm{D}$ levels in melanoma patients is of minimal importance.

Our study evaluated patients with larger AAAs which were treated surgically. This might have caused a selection bias and the results might not be representative of all AAA patients. A major advantage of our study was matching of patients and controls on sex and age minimizing the confounding effects attributed to these factors.

\section{Conclusions}

A better understanding about the pathophysiology of AAA will facilitate the development of pharmacotherapies for AAA. Also, this knowledge could be used for a better risk stratification. By introducing a national screening program in every country, AAA could be detected earlier. It is also important to consider the possible complications arising from CKD, both after open aneurysm repair, and EVAR. This group of patients should be given special attention and risk factor analysis should be carried out. The risk of rupture should be 


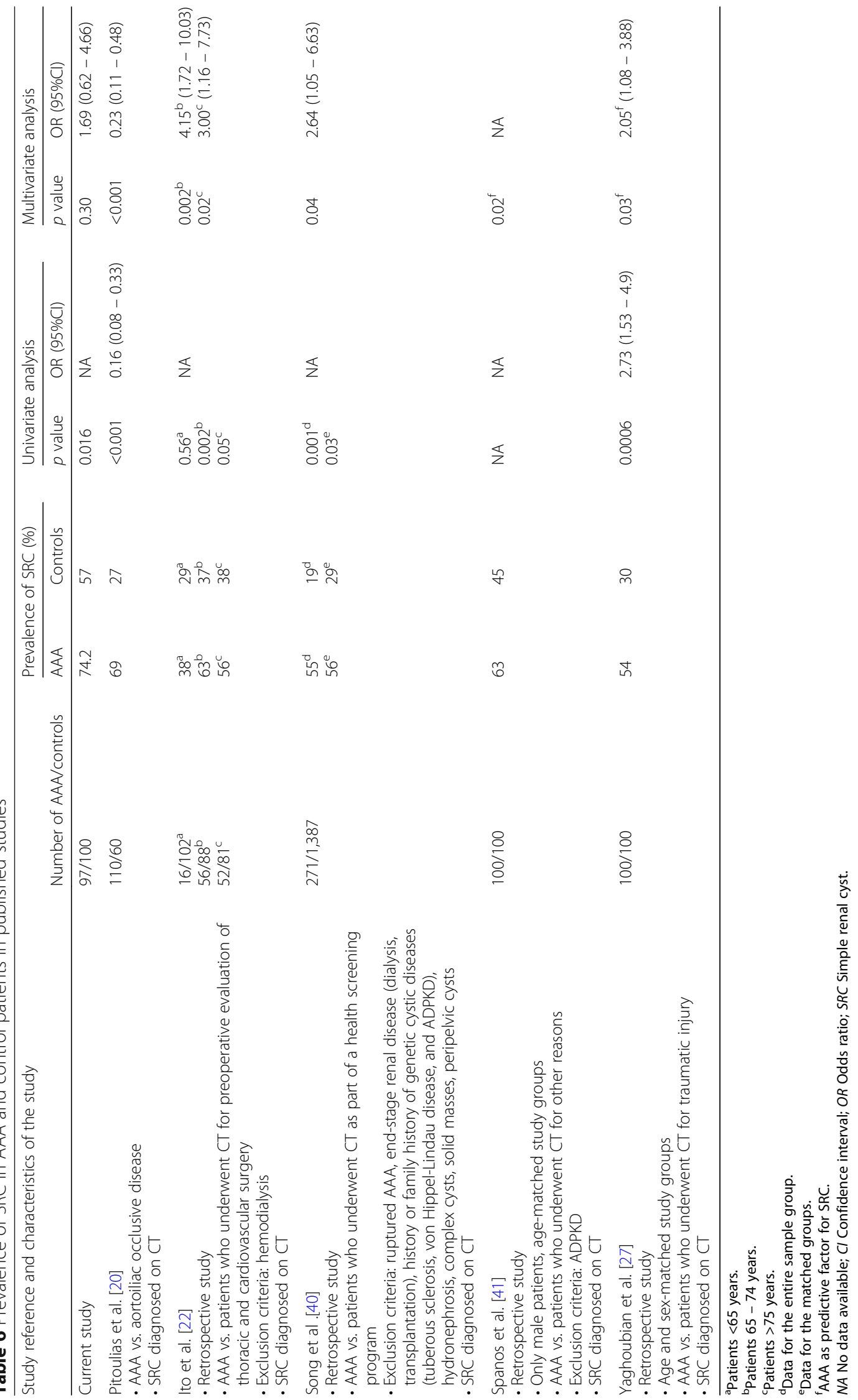


high enough to justify the risk of surgery. Further research is also needed on patients with small AAA who develop problems in kidney function. It remains to be determined if renal function is also affected by an expansion and different types of AAA where the renal arteries are involved.

\section{Supplementary information}

Supplementary information accompanies this paper at https://doi.org/10. 1186/s12882-020-01841-6.

Additional file 1. Dataset containing all information on every patient

included in the study (Excel format).

Additional file 2: Table S1. Data dictionary, in alphabetical order Includes detailed information about collected data. Table S2. Comparison of height, weight, and BMI between the AAA and contro group. Table S3. SA-Scores. Table S4. ABO-blood groups. Table S5. Rhesus factor.

\section{Abbreviations}

AAA: Abdominal aortic aneurysm; ADPKD: Autosomal dominant polycystic kidney disease; ASA: American Society of Anesthesiologists; Cl: Confidence interval; CKD: Chronic kidney disease; COPD: Chronic obstructive pulmonary disease; CT: Computed tomography; CTA: Computed tomography angiography; EVAR: endovascular aneurysm repair; OR: Odds ratio; PAD: Peripheral artery disease; SRC: Simple renal cyst

\section{Acknowledgements}

The authors would like to acknowledge support from the German Research Foundation (DFG) and the Open Access Publication Funds of Charité Universitätsmedizin, Berlin.

\section{Authors' Contributions}

Conceptualization: $1 H$, Data curation: MM, DW, AD, Formal analysis: MM, AS, Funding acquisition: not applicable, Investigation: MM, DW, AD, Methodology: $I H$, Project administration: $\Vdash H$, Resources: $\Vdash H$, CEA, Software: AS, Supervision: $\| H$, Validation: $\| H, M M, A S$, Visualization: MM, Writing original draft: MM, VM, Writing - review \& editing: $I H, H K, C E A, A S, D W, A D$, AG. The authors read and approved the final manuscript.

\section{Funding}

This research received no specific grant from any funding agency in the public, commercial, or not-for-profit sectors.

\section{Availability of data and materials}

All relevant data are within the paper and the files part of the Supporting Information.

\section{Ethics approval and consent to participate}

The study was approved by the Charité Ethics Committee (approval number: EA1/309/16). Since the study was a retrospective review of medical and imaging records, no informed consent from the patients was required according to the study approval.

\section{Consent for publication}

Not applicable.

\section{Competing interests}

None

\section{Author details}

${ }^{1}$ Vascular Surgery Clinic, Klinik für Gefäßchirurgie, Campus Charité Benjamin Franklin, Hindenburgdamm 30, 12200 Berlin, Germany. 'Surgical Clinic, Campus Charité Mitte and Campus Virchow-Klinikum, Berlin, Germany. ${ }^{3}$ Institute of Radiology, Campus Charité Mitte, Berlin, Germany. ${ }^{4}$ Institute of Medical Biometrics and Clinical Epidemiology, Campus Charité Benjamin Franklin, Charité - Universitätsmedizin Berlin, corporate member of Freie
Universität Berlin, Humboldt-Universität zu Berlin, and Berlin Institute of Health, Berlin, Germany. ${ }^{5}$ Division of Molecular Biology and Human Genetics, Department of Biomedical Sciences, Faculty of Medicine and Health Sciences, Stellenbosch University, Tygerberg, South Africa.

Received: 11 October 2019 Accepted: 5 May 2020

Published online: 29 May 2020

\section{References}

1. Moll FL, Powell JT, Fraedrich G, Verzini F, Haulon S, Waltham M, et al. Management of abdominal aortic aneurysms clinical practice guidelines of the European society for vascular surgery. Eur J Vasc Endovasc Surg. 2011; 41(Suppl 1):S1-S58.

2. Lilja F, Wanhainen A, Mani K. Changes in abdominal aortic aneurysm epidemiology. J Cardiovasc Surg (Torino). 2017;58:848-53.

3. Lederle FA. The rise and fall of abdominal aortic aneurysm. Circulation. 2011; 124:1097-9.

4. Cornuz J, Sidoti Pinto C, Tevaearai H, Egger M. Risk factors for asymptomatic abdominal aortic aneurysm: systematic review and meta-analysis of population-based screening studies. Eur J Public Health. 2004:343-9.

5. Fleming C, Whitlock EP, Beil TL, Lederle FA. Screening for abdominal aortic aneurysm: a best-evidence systematic review for the U.S. Preventive Services Task Force. Ann Intern Med. 2005;142:203-11.

6. Keisler B, Carter C. Abdominal aortic aneurysm. Am Fam Physician. 2015;91:538-43.

7. Reimerink JJ, van der Laan MJ, Koelemay MJ, Balm R, Legemate DA. Systematic review and meta-analysis of population-based mortality from ruptured abdominal aortic aneurysm. Br J Surg. 2013;100:1405-13.

8. Acosta S, Ogren M, Bengtsson H, Bergqvist D, Lindblad B, Zdanowski Z Increasing incidence of ruptured abdominal aortic aneurysm: a populationbased study. J Vasc Surg. 2006:44:237-43.

9. Guirguis-Blake JM, Beil TL, Sun X, Senger CA, Whitlock EP. Primary care screening for abdominal aortic aneurysm: an evidence update for the U.S. preventive services task force. Evidence Synthesis No. 109. AHRQ Publication No. 14-05202-EF-1. Rockville: Agency for Healthcare Research and Quality; 2014. https://pubmed.ncbi.nlm.nih.gov/24555205/.

10. Siso-Almirall A, Kostov B, Navarro Gonzalez M, Cararach Salami D, Perez Jimenez A, Gilabert Sole R, et al. Abdominal aortic aneurysm screening program using hand-held ultrasound in primary healthcare. PLoS One. 2017; 12:e0176877.

11. Lederle FA. Screening for AAA in the USA. Scand J Surg. 2008;97:139-41.

12. Benson RA, Poole R, Murray S, Moxey P, Loftus IM. Screening results from a large United Kingdom abdominal aortic aneurysm screening center in the context of optimizing United Kingdom National Abdominal Aortic Aneurysm Screening Programme protocols. J Vasc Surg. 2016;63:301-4.

13. Simoni G, Pastorino C, Perrone R, Ardia A, Gianrossi R, Decian F, et al. Screening for abdominal aortic aneurysms and associated risk factors in a general population. Eur J Vasc Endovasc Surg. 1995;10:207-10.

14. Alcorn HG, Wolfson SK Jr, Sutton-Tyrrell K, Kuller LH, O'Leary D. Risk factors for abdominal aortic aneurysms in older adults enrolled in The Cardiovascular Health Study. Arterioscler Thromb Vasc Biol. 1996;16: 963-70.

15. Blanchard JF, Armenian HK, Friesen PP. Risk factors for abdominal aortic aneurysm: results of a case-control study. Am J Epidemiol. 2000;151:575-83.

16. Lederle FA, Johnson GA, Wilson SE, Chute EP, Hye RJ, Makaroun MS, et al. The aneurysm detection and management study screening program. Arch Intern Med. 2000;160:1425-30.

17. Kent KC, Zwolak RM, Egorova NN, Riles TS, Manganaro A, Moskowitz AJ, et al. Analysis of risk factors for abdominal aortic aneurysm in a cohort of more than 3 million individuals. J Vasc Surg. 2010;52:539-48.

18. Wahlgren CM, Larsson E, Magnusson PK, Hultgren R, Swedenborg J. Genetic and environmental contributions to abdominal aortic aneurysm development in a twin population. J Vasc Surg. 2010;51:3-7.

19. Meijer CA, Kokje VB, van Tongeren RB, Hamming JF, van Bockel JH, Moller $\mathrm{GM}$, et al. An association between chronic obstructive pulmonary disease and abdominal aortic aneurysm beyond smoking: results from a casecontrol study. Eur J Vasc Endovasc Surg. 2012;44:153-7.

20. Pitoulias GA, Donas KP, Chatzimavroudis G, Torsello G, Papadimitriou DK The role of simple renal cysts, abdominal wall hernia, and chronic obstructive pulmonary disease as predictive factors for aortoiliac aneurysmatic disease. World J Surg. 2012;36:1953-7. 
21. Schuster JJ, Raptopoulos, V., Baker, S.P. Increased prevalence of cholelithiasis in patients with abdominal aortic aneurysm: sonographic evaluation. Am J Roentgenol 1989;152:509-511.

22. Ito T, Kawaharada N, Kurimoto $Y$, Watanabe A, Tachibana $K$, Harada $R$, et al. Renal cysts as strongest association with abdominal aortic aneurysm in elderly. Ann Vasc Dis. 2010;3:111-6.

23. Laucks SP Jr, McLachlan MS. Aging and simple cysts of the kidney. Br J Radiol. 1981;54:12-4.

24. Tada S, Yamagishi J, Kobayashi H, Hata Y, Kobari T. The incidence of simple renal cyst by computed tomography. Clin Radiol. 1983;34:437-9.

25. Carrim ZI, Murchison JT. The prevalence of simple renal and hepatic cysts detected by spiral computed tomography. Clin Radiol. 2003;58:626-9.

26. Chang CC, Kuo JY, Chan WL, Chen KK, Chang LS. Prevalence and clinical characteristics of simple renal cyst. J Chin Med Assoc. 2007;70:486-91.

27. Yaghoubian A, de Virgilio C, White RA, Sarkisyan G. Increased incidence of renal cysts in patients with abdominal aortic aneurysms: a common pathogenesis? Ann Vasc Surg. 2006;20:787-91.

28. Chin HJ, Ro H, Lee HJ, Na KY, Chae DW. The clinical significances of simple renal cyst: Is it related to hypertension or renal dysfunction? Kidney Int. 2006;70:1468-73.

29. Mosharafa AA. Prevalence of renal cysts in a Middle-Eastern population: an evaluation of characteristics and risk factors. BJU Int. 2008;101:736-8.

30. Terada N, Ichioka K, Matsuta Y, Okubo K, Yoshimura K, Arai Y. The natural history of simple renal cysts. J Urol. 2002;167:21-3.

31. Pedersen JF, Emamian SA, Nielsen M, B. Significant association between simple renal cysts and arterial blood pressure. Br J Ur 1997;79:688-692.

32. Liapis $C D$, Paraskevas Kl. The pivotal role of matrix metalloproteinases in the development of human abdominal aortic aneurysms. Vasc Med. 2003;8:267-71.

33. Harada H, Furuya M, Ishikura H, Shindo J, Koyanagi T, Yoshiki T. Expression of matrix metalloproteinase in the fluids of renal cystic lesions. J Urol. 2002; 168:19-22.

34. Müller V, Miszczuk M, Althoff C, Stroux A, Greiner A, Kuivaniemi H, et al. Comorbidities associated with large abdominal aortic aneurysms. Aorta (Stamford). 2019;7:108-14.

35. Bosniak MA. The current radiological approach to renal cysts. Radiology. 1986;158:1-10

36. Alnassar S, Bawahab M, Abdoh A, Guzman R, Al Tuwaijiri T, Louridas G. Incisional hernia postrepair of abdominal aortic occlusive and aneurysmal disease: five-year incidence. Vascular. 2012;20:273-7.

37. Barisione C, Garibaldi S, Brunelli C, Balbi M, Spallarossa P, Canepa M, et al. Prevalent cardiac, renal and cardiorenal damage in patients with advanced abdominal aortic aneurysms. Intern Emerg Med. 2016;11:205-12.

38. Chun KC, Teng KY, Chavez LA, Van Spyk EN, Samadzadeh KM, Carson JG, et al. Risk factors associated with the diagnosis of abdominal aortic aneurysm in patients screened at a regional Veterans Affairs health care system. Ann Vasc Surg. 2014;28:87-92.

39. Takeuchi H, Okuyama M, Uchida HA, Kakio Y, Umebayashi R, Okuyama Y, et al. Chronic Kidney Disease Is Positively and Diabetes Mellitus Is Negatively Associated with Abdominal Aortic Aneurysm. PLoS One. 2016;11: e0164015

40. Song BG, Park YH. Presence of renal simple cysts is associated with increased risk of abdominal aortic aneurysms. Angiology. 2020;71:465-70. https://doi.org/ 10.1177/0003319714548565.

41. Spanos K, Rountas C, Saleptsis V, Athanasoulas A, Fezoulidis I, Giannoukas AD. The association of simple renal cysts with abdominal aortic aneurysms and their impact on renal function after endovascular aneurysm repair. Vascular. 2016;24:150-6.

42. Brownstein AJ, Bin Mahmood SU, Saeyeldin A, Velasquez Mejia C, Zafar MA, Li Y, et al. Simple renal cysts and bovine aortic arch: markers for aortic disease. Open Heart. 2019;6:e000862.

43. Kurata A, Inoue S, Ohno S, Nakatsubo R, Takahashi K, Ito T, et al. Correlation between number of renal cysts and aortic circumferences measured using autopsy material. Pathol Res Pract. 2013;209:441-7.

44. Torres VE, Wilson DM, Hattery RR, Segura JW. Renal stone disease in autosomal dominant polycystic kidney disease. Am J Kidney Dis. 1993;22: 513-9.

45. Kato A, Takita T, Furuhashi M, Maruyama Y, Hishida A. Abdominal aortic aneurysms in hemodialysis patients with autosomal dominant polycystic kidney disease. Nephron. 2001;88:185-6.

46. Reeps C, Maier A, Pelisek J, Hartl F, Grabher-Meier V, Wall WA, et al. Measuring and modeling patient-specific distributions of material properties in abdominal aortic aneurysm wall. Biomech Model Mechanobiol. 2013;12: 717-33.

47. Mehta M, Veith FJ, Lipsitz EC, Ohki T, Russwurm G, Cayne NS, et al. Is elevated creatinine level a contraindication to endovascular aneurysm repair? J Vasc Surg. 2004;39:118-23.

48. Jean G, Souberbielle JC, Chazot C. Vitamin D in chronic kidney disease and dialysis patients. Nutrients. 2017;9:328. https://doi.org/10.3390/nu9040328.

49. Wong $Y Y$, Flicker L, Yeap BB, McCaul KA, Hankey GJ, Norman PE. Is hypovitaminosis D associated with abdominal aortic aneurysm, and is there a dose-response relationship? Eur J Vasc Endovasc Surg. 2013;45:657-64.

\section{Publisher's Note}

Springer Nature remains neutral with regard to jurisdictional claims in published maps and institutional affiliations.
Ready to submit your research? Choose BMC and benefit from:

- fast, convenient online submission

- thorough peer review by experienced researchers in your field

- rapid publication on acceptance

- support for research data, including large and complex data types

- gold Open Access which fosters wider collaboration and increased citations

- maximum visibility for your research: over $100 \mathrm{M}$ website views per year

At BMC, research is always in progress.

Learn more biomedcentral.com/submissions 